\section{Edycaçäa s.}

DossIÊ

\section{Editora}

Maria Inês Côrte Vitoria

PUCRS, RS, Brasil

\section{Editora Colaboradora}

Pricila Kohls dos Santos

PUCRS, RS, Brasil

\section{Equipe Editorial}

Carla Spagnolo

PUCRS, Brasil

Rosa Maria Rigo

PUCRS, Brasil

\section{ISSN 2179-8435}

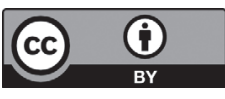

Este artigo está licenciado sob forma de uma licenç Creative Commons Atribuição 4.0 Internacional, que permite uso irrestrito, distribuiçăo e reproduçāo seja corretamente citada.

\section{Dimensões do engajamento estudantil para o contexto brasileiro: a emergência política da participação para a inovação pedagógica na Educação Superior} Dimensions of student engagement for the Brazilian context: the political
emergence of participation for pedagogical innovation in Higher Education

Bernardo Sfredo Miorando ${ }^{1}$

Denise Leite ${ }^{2}$

\section{RESUMO}

Este ensaio apresenta perspectivas para a incorporação do conceito de student engagement no repertório teórico dos estudos sobre educação superior no Brasil. Discutindo as raízes do termo, propõe que seja traduzido como engajamento estudantil, em referência à tradição dos estudos latino-americanos sobre o estudante universitário e seus movimentos políticos. Revisa a literatura da corrente norte-americana e europeia sobre o student engagement, bem como as obras seminais latino-americanas que tratam do "estudante engajado" desde a Reforma de Córdoba. Apresenta as ideias de participação e inovação pedagógica como possíveis caminhos de desenvolvimento conceitual e prático do conceito de engajamento estudantil. Explora as relações entre essas noções e a realidade brasileira. Ressalta a formação política para a participação cidadã como componente fundamental do engajamento estudantil, considerando que a constituição do estudante como sujeito político é decisiva para o futuro da educação superior.

Palavras-chave: engajamento estudantil; educação superior; inovação pedagógica; participação.

\footnotetext{
1 Doutorando no Programa de Pós-Graduação em Educação da Universidade Federal do Rio Grande do Sul. Bolsista Capes. 2 Docente Permanente do Programa de Pós-Graduação em Educação da Universidade Federal do Rio Grande do Sul. Pesquisadora $1 \mathrm{~A}$ CNPq.
} 


\section{ABSTRACT}

In this essay, we present perspectives for the incorporation of the concept of student engagement in the theoretical repertoire of higher education studies in Brazil. Discussing the roots of the term, we propose it to be translated as "engajamento estudantil", in reference to the tradition of Latin American studies on university students and their political movements. We review the North American and European literature on student engagement, as well as Latin American seminal works dealing with the "engaged student" since the Reform of Cordoba. We present the ideas of participation and pedagogical innovation as possible pathways for conceptual and practical development of the concept of student engagement. We explore the relationships between these notions and Brazilian reality. We emphasize the political education for citizen participation as a fundamental component of student engagement, considering that the constitution of the student as a political subject is decisive for the future of higher education.

Keywords: student engagement; higher education; pedagogical innovation; participation.

\section{Introdução: os termos do engajamento}

“Ora, no mundo de hoje, ser intelectual é também tomar esse partido do progresso. Isso significa igualmente atenção aos pobres e às minorias. [...] Ser intelectual é exercer diariamente rebeldia contra conceitos assentados, tornados respeitáveis, mas falsos. É, também, aceitar o papel de criador e propagador do desassossego e o papel de produtor do escândalo, se necessário. [...] para os intelectuais, não basta culpar o mundo, ele tem de ser entendido. Esse é o trabalho essencial da universidade: interpretar este mundo e a partir dai propor modificá-lo. [...] Sem buscar uma interpretação do mundo a partir do nosso lugar, que modificaria, também, a interpretação do nosso lugar, não contribuiremos validamente ao conhecimento do mundo." (SANTOS, 1997, p. 18, 20)

"A característica diferencial da Universidade latino-americana é sua forma democrática de governo, instituída através da coparticipação de professores e alunos em todos os órgãos deliberativos. Esta instituição assegurou às universidades que a adotaram um alto grau de percepção de suas responsabilidades ante a sociedade nacional, deu maior coesão interna a seus componentes e lhe proporciona, agora, a possiblidade de promover sua renovação estrutural." (RIBEIRO, 1975, p. 158) 
Z $\mathrm{m}$ âmbito internacional, a discussão do student engagement parece se consolidar como um tema estabelecido

dentro da especialidade dos estudos de educação superior. Não obstante, no Brasil, a temática aparenta ser ainda emergente, e carecer de alguma estabilização para seu efetivo trabalho em pesquisas acadêmicas. Ao trazê-la para o campo nacional, parece oportuno problematizar uma questão de fundo: tensionar o enquadramento do student engagement como fenômeno, observando-o para além do envolvimento particulares do indivíduo em situações de desenvolvimento pessoal.

Chama-se atenção para as raízes e os desdobramentos públicos do engajamento no plano coletivo do desenvolvimento institucional. Assim, é possível fazer transitar o student engagement entre as duas grandes "ilhas" do "arquipélago" da pesquisa em educação superior: ensino-aprendizagem e políticas (MACFARLANE, 2012). No ângulo proposto aqui, estudar o student engagement é estudar dinâmicas políticas em que a universidade se renova pela ação estudantil instituinte.

Seguindo essa linha de raciocínio, opta-se aqui por proceder a tradução do termo de forma radical, como "engajamento estudantil", considerando a carga política que a palavra engajamento traz, atestada por uma de suas possíveis acepções dicionarizadas:

Situação de quem sabe que é solidário com as circunstâncias sociais, históricas e nacionais em que vive, e procura, pois, ter consciência das consequências morais e sociais de seus princípios e atitudes (opõe-se à atitude individualista liberal-burguesa) (BUARQUE DE HOLLANDA FERREIRA, 1975).

Essa opção sublinha a ideia de que a realidade brasileira - e latino-americana como um todo - demanda uma perspectiva crítica que faça explícita a implicação do engajamento estudantil na educação superior com os fenômenos do ativismo estudantil, da representação estudantil e da luta por reconhecimento dentro das instituições de educação superior. Tal escolha considera também a disputa conceitual que existe no debate sobre o student engagement, qualificada por Trowler (2015) na figura marxiana de "representação caótica do todo". Reconhece que, como registram Wolf-Wendel, Ward e Kinzie (2009), há sobreposições entre as noções de envolvimento, engajamento e integração quanto a estudantes de educação superior. Para as autoras, engajamento envolve estudantes e instituições, "duas partes que entram em um acordo sobre a experiência educacional" (WOLF-WENDEL, WARD; KINZIE, 2009, p.413). Em tal sentido contratual, os ambientes institucionais seriam inclusivos e afirmativos, com clareza quanto ás expectativas de desempenho. 
O conceito de engajamento estudantil é sobre encorajar a reflexão e a ação institucionais sobre a prática efetiva. Especificamente, ele considera o papel da instituição em canalizar a participação estudantil em prática educacional efetiva. Como resultado, é um conceito relacionado à melhoria institucional porque aponta imediatamente atividades que podem ser influenciadas diretamente e indiretamente para melhorar a aprendizagem estudantil (WOLF-WENDEL; WARD; KINZIE, 2009, p. 414).

Direcionar o olhar teórico para uma acepção específica é um movimento consciente na disputa epistemológica pelas possibilidades de aplicação do conceito: aborda a definição canônica, aportando os referentes culturais carregados no léxico local para melhor dar conta do contexto nacional. Isso considera tanto as advertências de Zepke (2018) sobre as tendências de captura do student engagement por disposições neoliberais quanto a argumentação de Buckley (2018) sobre suas potencialidades críticas. Interessa especialmente explorar no engajamento estudantil as forças identificadas por Ribeiro (1975) e Santos (1997) como capazes de fortalecer a universidade pela sua capacidade de se transformar com o metabolismo da crítica. Busca também aproximá-la de um universo semântico que projeta a educação superior como bem e espaço público e se associa a ideias de conscientização, solidariedade, responsabilidade, cidadania e democracia.

\section{Desenvolvimentos teóricos: o engajamento estudantil na literatura do norte e o estudante engajado na literatura do sul}

\subsection{Norte: Estados Unidos e Europa}

Um breve recorrido histórico pela literatura europeia e norte-americana conferiria a William G. Perry o pioneirismo dos estudos sobre o estudante da educação superior. Foi Perry, professor da escola de Educação de Harvard, que em 1970 apresentou "Forms of intellectual and ethical development in the college years: a scheme". Em anos seguintes vários autores iriam dedicar-se ao tema, abordando-o sob diferentes olhares. Na mesma década, Burton Clark (1973), sugeriu que as investigações sobre o estudante poderiam ser parte do campo de estudos em formação denominado Sociologia da Educação Superior. Citou trabalhos que abordaram o estudante no college e na universidade, tipologias e categorizações, valores e atitudes.

Em anos seguintes discutiram-se: formas de estudar (MARTON; SALJO, 1976); impacto dos colleges sobre o estudante (FELDMAN; NEWCOMB, 1976); o estudante como um ser aprendente, contextos e personalidades (ENTWISTLE, 1979; ENTWISTLE; RAMSDEN, 1983; ENTWISTLE, MCCUNE, SCHEJA, 2006); como as instituições afetam os estudantes (PASCARELLA; TERENZINI, 1991). Na vertente psicológica e educacional, a 
Society for Research into Higher Education publicou o livro "Student Learning Research in education and cognitive psychology", editado por Richardson, Eysenck e Piper (1987). A obra trazia o estado da arte da pesquisa sobre o estudante universitário, reunindo estudos de Diana Laurillard, Robert Sternberg, Noel Entwistle, Roger Saljo e Dai Hounsell dentre outros.

Um novo enfoque sobre o estudante, desta vez a partir do olhar sobre o entorno, a instituição e o que ela oferece, veio a ter lugar com Alexander Astin (1993). O autor mostrou os desafios que as universidades e os colleges oferecem aos estudantes em "What Matters in College? Four Critical Years Revisited", onde caracterizou os campos de estudos sobre o estudante universitário. Provavelmente deve-se a Astin, a "teoria do envolvimento do estudante", assim entendida: "quanto mais o estudante for desafiado em aulas, atividades extracurriculares e sociais, maior será sua autodeterminação e seu protagonismo e, por consequência, maior a sua aprendizagem".

Já utilizando o termo engagement, destacou-se o National Survey of Student Engagement (NSSE) elaborado por Georges Kuh com a finalidade de levantar as atividades que as instituições proporcionam aos estudantes para sua aprendizagem e desenvolvimento, como os estudantes se envolvem com a instituição e como usam seu tempo. Dirigido aos estudantes do college, nem sempre o estudo foi entendido como válido para o sistema universidade. Segundo a NSSE,

Engajamento estudantil representa duas características críticas da qualidade colegiada. A primeira é a quantidade de tempo e esforço que os estudantes dedicam aos estudos e outras atividades de propósito educativo. A segunda é como a instituição aplica seus recursos e organiza o currículo e outras oportunidades de aprendizagem para fazer com que os estudantes participem em atividades que, de acordo com décadas de pesquisas, estão ligadas à aprendizagem estudantil (NSSE, 2018).

O tema "estudante" é abordado na literatura sob diversos ângulos. Inicialmente, a preocupação era com o ser psicológico, a persona, suas formas de aprendizagem. Depois, com sua caracterização como um cidadão consumidor, um cliente dos serviços oferecidos pela instituição universidade. Em vários estudos, encontramos a preocupação com os contextos de aprendizagem oferecidos aos estudantes como motivação para seu engajamento. Tal ênfase ganha importância quando as instituições estão a receber alunos de todas as partes do mundo, quando a inclusão social se faz intensamente presente; quando a cobrança do custo aluno evadido ou do custo aluno não concluinte ao tempo esperado de anos na universidade pressiona os gestores e desenvolvedores de currículos.

As preocupações da pesquisa nos estudos contemporâneos têm sido o envolvimento dos estudantes nas tarefas acadêmicas que lhe são específicas e como docentes, orientadores, tutores e a comunidade acadêmica em geral podem 
contribuir para envolver os estudantes em atividades acadêmicas nos níveis institucional, departamental e de curso. Considerando a consequentes diferenças da atuação nessas instâncias, Healey, Mason O'Connor e Bradfoot (2010, p.22) distinguem três níveis para a abordagem do engajamento estudantil: micro, "com a própria aprendizagem e a de outros estudantes"; meso "com o asseguramento de qualidade e com processos de melhoria"; e macro, "com o desenvolvimento de estratégias".

Ao tentar colocar um frame sobre os vários estudos disponíveis, Kahu (2011) adjetiva quatro perspectivas: comportamental, psicológica, sociocultural e holística. Em um quadro conceitual, o engajamento estudantil seria entendido como uma combinação de afeto - entusiasmo, interesse, pertença -, cognição - aprendizagem profunda, autorregulação - e comportamento - tempo e esforço, interação, participação. Zepke (2014) entende que o student engagement seria "uma rede complexa de perspectivas proximamente conectadas, ainda que distintas" (p. 697), que "parece escapar à crítica séria" (p.698).

Haveria uma ortodoxia acadêmica que incluiria possíveis inconsistências e a ausência de uma referencialidade explícita e aceita pela maioria dos pesquisadores do campo (KAHU, 2011; TROWLER, 2015; ZEPKE, 2011, 2014, 2018). Chen e Mathies (2016), por exemplo, apontam para uso inadequado de instrumentos de aferição do student engagement - no caso, da NSSE - para promover o ranqueamento de universidades. Alertam também para o fato de que a validade de modelos de avaliação do engajamento estudantil não é necessariamente transferível entre diferentes contextos acadêmicos. Buckley (2017), considerando os aspectos ideológicos da pesquisa em student engagement argui que os pesquisadores têm tanto valorizado a perspectiva neoliberal quanto se oposto ao neoliberalismo ao analisar a participação estudantil no processo de tomada de decisão quanto a ensino aprendizagem.

\subsection{América Latina}

Na América Latina, os estudos sobre o estudante seguem uma trajetória bastante distinta do cânone norteocidental. Poderia ter sido um reflexo direto da conhecida Reforma de Córdoba, o movimento liderado pelos estudantes na Universidade de Córdoba, Argentina, em 1918. O movimento estudantil de Córdoba, cujo centenário foi comemorado em junho de 2018, caracterizou uma forma de engajamento político-social dos estudantes, uma forma de insurgência dos jovens contra a o ordenamento político-pedagógico então vigente na vida acadêmica. $\mathrm{O}$ engajamento dos estudantes resultou em um movimento que defendia a democracia dentro e fora da sala de aula e que reformou a universidade do início do século XX em aspectos relativos à gestão, à didática e à projeção política e social da universidade na sociedade. Os estudantes que escreveram o Manifesto Liminar aos homens livres de América tiveram suas ideias levadas a outros países atingindo, além das demais universidades de Argentina, aos estudantes 
de Uruguai, Peru, Cuba, Colômbia, México, chegando posteriormente a Brasil (RIBEIRO, 1975; TUNNERMANN BERNHEIM, 2008).

Desde o início do século passado, os estudantes latino-americanos e caribenhos foram entendidos e descritos por vários autores como jovens politicamente ativos, engajados e influentes nas decisões universitárias e na sociedade (INGENIEROS, 2017 [1924]; KROTSCH, 2004, MARIÁTEGUI, 2017 [1928]). Com sua origem familiar, sua classe social, suas crenças políticas, esses jovens assumiram uma atitude antecipativa e influenciaram as decisões políticoacadêmicas. Desempenharam uma liderança inconteste naqueles países que então experienciavam seus primeiros anos de vida republicana, vivendo a construção da democracia no Novo Mundo. Sua inserção e engajamento social e político, sua participação desde o espaço estudantil teria contribuído ao fortalecimento das universidades e destas às nações, servindo ao combate às ditaduras e a todas às formas de imperialismo, colonialidade, discriminação e opressão social. Na Argentina destacou-se o trabalho de Juan Carlos Portantiero (1978) que produziu a obra referencial "Estudiantes y política en América Latina,1918-1938. El proceso de la reforma universitária".

$\mathrm{Na}$ América Latina, os estudos sobre o estudante assumiram a concepção do "transindivíduo" (GOLDMANN, 1984), sujeito que frequenta a instituição universitária por um determinado período de tempo e representa uma visão de transitoriedade. Este foi o referencial para olhar o estudante como um ser social, capaz de produzir uma forma de cultura, a cultura estudantil gerada nos anos acadêmicos. Esta cultura incluiu engajamento e resistência. No Brasil, incluiu a perspectiva de transformação da universidade e também da sociedade, tal como sugere o estudo de Marialice Forachi (1965) intitulado "O estudante e a transformação da sociedade brasileira". Esta publicação marcou a visão sociológica brasileira sobre o ser social estudante e sua práxis, à época caracterizada em ações da juventude próreformas.

O tema também começou a aparecer com certa frequência entre pesquisadores de destaque e foi propício a uma senda de estudos com cunho político-social reformista. José Arthur Rios (1971) descreveu os estudantes em sua relação com a sociedade brasileira na monografia intitulada The University Student and Brazilian society, produzida e publicada sob o patrocínio do Latin American Studies Center de Michigan, nos Estados Unidos da América. José Guilhon de Albuquerque (1977) lançou "O movimento estudantil e consciência social na América Latina: teoria e método sociológico". Arthur José Poerner (1979) descreveu a história da participação política dos estudantes brasileiros. A literatura consolidou a reflexão sobre os estudantes no sentido político-sociológico e teve vários seguidores (SANFELICE, 1986; MARTINS FILHO, 1987; UNE, 1987; LEITE, 1990; 1992; 2018).

O tema "estudante engajado" e participante da luta pela transformação social na América Latina é anterior e diverso das bases teóricas da pesquisa internacional sobre o student engagement. Na esteira dos autores revisados, uma vertente investigativa foi plasmada. Os estudantes foram vistos sob o aspecto de sua politização, sua práxis, e, na 
perspectiva dos movimentos estudantis. Estes movimentos, para além do âmbito estrito da sala de aula universitária, projetaram-se no contexto histórico da educação superior das nações latino-americanas.

Enquanto a temática do estudante se desenvolvia no Novo Mundo, e seu poder ativista, há que dar-se um crédito especial à Habermas que, no Velho Mundo, assombrado com a forca dos jovens universitários e após investigar os estudantes germânicos, reconhecia "o poder jovem". Em obra em colaboração (HABERMAS et al., 1961) e, mais tarde, em publicações e conferências realizadas na América do Norte, Habermas defendeu que a universidade deveria exercer influência sobre a consciência política e social dos estudantes. Se ela obtivesse sucesso nesta missão, resultaria, como consequência, um comportamento político estudantil favorável à democracia. Isto é, caberia à universidade, seus docentes, seu ambiente cultural e social, promover a discussão e a prática de temas políticos.

\section{Sínteses de engajamento estudantil para a educação superior brasileira: participação para a inovação pedagógica}

Seguindo a perspectiva delineada na seção introdutória, de aproximar a literatura internacional do student engagement à figura latino-americana do estudante engajado social e politicamente, apresentam-se aqui alguns elementos que podem atender ao estudo da educação superior brasileira. Parte-se aqui da retomada das duas diferentes perspectivas analíticas que Aswhin e McVitty (2015) propõem para enquadrar eventos de engajamento estudantil ponderando "o que é 'formado' por meio do engajamento estudantil” (p.345).

Uma primeira diferenciação se dá entre três formações a que podem se dedicar os estudantes: a de entendimentos individuais, que levam a melhorar resultados de aprendizagem; a de currículos, que levam a propor atividades de ensino; e a de comunidades, que levam ao engajamento na tentativa de colaborar na moldagem das instituições e sociedades de que fazem parte. A segunda distinção se daria considerando

[...] as formas pelas quais o objeto do engajamento estudantil é afetado pelos estudantes que com ele se engajam. Com isso, destacam-se três amplos graus de engajamento: consulta, pela qual estudantes se engajam com um objeto fixo que não se modifica pelo seu engajamento; parceria, pela qual estudantes participam na transformação de um objeto de engajamento pré-existente; e liderança, pela qual estudantes criam novos objetos de engajamento (ASWHIN; MCVITTY, 2015, p.346).

Aswhin e McVitty (2015, p. 347) afirmam ainda que "neste último grau, os estudantes definem em seus próprios termos o que o engajamento arreta e quais seus resultados esperados”. A partir daí, associa-se o entendimento de que 
o estudante engajado pode agir como intelectual público na perspectiva de desencadear processos de mudança social a partir das intervenções com que defende suas pautas político-pedagógicas nas instituições educativas. Pode gerar situações de inovação pedagógica, isto é,

[...] um processo de rompimento com o status quo de uma dada situação educativa com busca de reconfiguração e disputa entre saberes e poderes. Uma inovação é pedagógica porque reconfigura ou favorece a disputa entre saberes e poderes na sala de aula, porque convive e dá guarida às descontinuidades e incertezas do conhecimento, porque entra em conflito com os paradigmas tradicionais e acolhe o pensar e o fazer democrático (LEITE; GENRO; BRAGA, 2011, p. 38).

Dentro dos quadros da inovação pedagógica em um paradigma de democracia forte, associa-se ao engajamento estudantil um papel protagonista, em que

[...] o inovador será a possibilidade conquistada de os sujeitos e os grupos sociais, assumirem e defenderem com conhecimento de causa, as posições assumidas. Assumirem a explicitação de suas convicções, assumirem o humano da relação educativa em todas as suas dimensões (LEITE et al., 1997, p. 93).

Uma tal forma de protagonismo se associa à noção de participação, "entendida como direito e dever para consigo e para com os demais" (LEITE et al., 2009, p.219). É preciso, porém, reconhecer os limites dentro dos quais se circunscrevem as possibilidades dos estudantes brasileiros. Inovação pedagógica e participação estudantil são fenômenos educacionais constrangidos pelas severas condições sociais e políticas brasileiras. No Brasil, um dos desafios de refletir sobre o engajamento estudantil é que a própria sobrevivência material do estudante não pode ser dada como garantida. A sociedade brasileira é violenta, e numerosos estudantes foram vitimados pela criminalidade urbana. Ainda que um processo de interiorização tenha ocorrido no decênio 2004-2014, as instituições de educação superior se desenvolveram de forma concentrada nas grandes cidades até a década de 2000.

Em uma cidade grande e violenta, o direito cidadão de se engajar profundamente com a vida cultural e política de uma instituição de educação superior pode parecer um privilégio para aqueles vitoriosos que atravessarem todos os desafios cotidianos da sobrevivência no Brasil contemporâneo. Estudantes podem vir de origens socioeconômicas desfavorecidas; podem ser discriminados por sua raça, deficiência, orientação sexual, credo religioso ou atividade política; podem levar horas deslocando-se até suas instituições em um sistema de transporte público precário; podem encontrar pouco ou nenhum serviço de apoio, como alimentação ou moradia subsidiadas; podem ser atacados, e frequentemente roubados, nas vizinhanças de seus câmpus. 
Ao mesmo tempo, a universidade pode ser vista tanto como um adversário a conquistar quanto como um refúgio seguro. Por seu status social, a educação superior - especialmente em universidades públicas - é para a juventude brasileira uma força contraditória de opressão e redenção. Ela combina a promessa de alcançar uma classe social superior através da profissionalização à submissão a uma hierarquia conformada por códigos, regras e a autoridade dos professores. Por isso,

[...] a universidade brasileira precisa trabalhar com os valores da democracia forte traduzida em uma gestão e uma avaliação institucional em que a participação seja um direito pedagógico. A universidade brasileira precisa, tanto quanto a universidade latino-americana, preocupar-se com as camadas sociais que a ela ainda não tiveram acesso, precisa trabalhar de forma a produzir uma cultura de inclusão social interna e externa. Estimular o protagonismo de sujeitos ativos, através da avaliação institucional, pode produzir formas de democracia forte vicejando em suas entranhas e espraiando-se pela sociedade. Através da avaliação, a Universidade deve poder criar o direito pedagógico da inclusão através da participação, para melhorar ou transformar a ordem existente. Esta tarefa social [...] mescla ações pragmáticas com prática de democracia em ato contribuindo para a criação de uma nova cultura política nas instituições (LEITE, 2005, p. 128-129).

A sinalização da autora ao papel da avaliação manifesta o forte papel que este fenômeno desempena no funcionamento das instituições de educação superior brasileiras. De fato, se no Brasil não se conta com uma NSSE para aferir o engajamento estudantil, alguns dados gerais sobre o assunto podem ser tomados a partir de um instrumento de avaliação institucional regulatória: o Questionário do Estudante preenchido pelos concluintes de cursos de graduação que prestam o Exame Nacional de Desempenho do Estudante (Enade) no âmbito do Sistema Nacional de Avaliação da Educação Superior (Sinaes). Na Tabela 1, adiante, estão reunidos alguns marcadores (SFREDO MIORANDO, no prelo).

O autor ressalta que "entre as questões selecionadas, aquela com resultados menos favoráveis é a que lida com o engajamento politico dos estudantes na vida institucional", considerando que "os estudantes perceberam essa dimensão como não sendo tão propiciada pelas instituições de educação superior, e também mostraram estar menos informados sobre ela" (SFREDO MIORANDO, no prelo). Por certo, não se pode limitar o engajamento estudantil à representação estudantil, mas esta serve como importante indicativo - político - dos contornos da agência que se espera do estudante dentro de um projeto formativo e quais os direitos pedagógicos que lhes são próprios. Isso porque é através da atuação como representante em órgão colegiado que os estudantes podem impactar as decisões políticopedagógicas das instituições. A considerar pelos dados alcançados pela avaliação da graduação, o estado geral da 
cultura política das instituições de educação superior brasileiras não pode ser considerado o de uma democracia forte. Mais do que favorecer, parece carecer da inovação pedagógica e do engajamento estudantil necessário para produzi-la.

Tabela 1. Elementos de engajamento estudantil a partir do Sinaes.

\begin{tabular}{|c|c|c|c|c|c|c|c|c|}
\hline \multirow{2}{*}{ Questões } & \multicolumn{8}{|c|}{$\%$ de respostas } \\
\hline & 1 & 2 & 3 & 4 & 5 & 6 & 7 & 8 \\
\hline $\begin{array}{l}\text { As atividades acadêmicas desenvolvidas dentro e fora da sala de aula } \\
\text { possibilitaram reflexão, convivência e respeito à diversidade. }\end{array}$ & 1.0 & 1.6 & 3.0 & 8.0 & 18.5 & 66.3 & 0.8 & 0.7 \\
\hline $\begin{array}{l}\text { O curso ofereceu condições para os estudantes participarem de eventos internos } \\
\text { e/ou externos à instituição. }\end{array}$ & 2.5 & 3.3 & 4.7 & 10.1 & 18.1 & 59.3 & 1.0 & 1.0 \\
\hline $\begin{array}{l}\text { Foram oferecidas oportunidades para os estudantes participarem de programas, } \\
\text { projetos ou atividades de extensão universitária. }\end{array}$ & 3.5 & 3.4 & 4.7 & 9.9 & 17.1 & 58.5 & 1.4 & 1.5 \\
\hline $\begin{array}{l}\text { Foram oferecidas oportunidades para os estudantes participarem de projetos de } \\
\text { iniciação científica e de atividades que estimularam a investigação acadêmica. }\end{array}$ & 4.2 & 3.9 & 5.3 & 10.1 & 16.8 & 56.7 & 1.5 & 1.6 \\
\hline A instituição promoveu atividades de cultura, de lazer e de interação social. & 4.8 & 4.7 & 5.9 & 11.1 & 17.0 & 53.0 & 1.8 & 1.7 \\
\hline $\begin{array}{l}\text { A instituição ofereceu oportunidades para os estudantes atuarem como } \\
\text { representantes em órgãos colegiados. }\end{array}$ & 5.7 & 4.5 & 5.9 & 11.6 & 16.6 & 46.4 & 2.8 & 6.5 \\
\hline
\end{tabular}

Escala: 1 a 6 de discordo plenamente a concordo plenamente; resposta 7 significa "não sei"; resposta 8 significa "não se aplica".

Fonte: Elaborado por Sfredo Miorando (no prelo) com base em itens selecionados do Questionário do Estudante do Enade 2016/Inep (2017).

Se esta é a condição da graduação, etapa inicial da formação superior, qual seria o estado da pós-graduação, etapa avançada? Não é possível afirmar. No Brasil, a força indutiva do Estado, exercida através da avaliação regulatória, faz-se tão ou mais forte na pós-graduação do que na graduação. Porém, ao contrário do Sinaes, a avaliação da pósgraduação não dispõe de instrumentos que afiram o engajamento estudantil com vistas à sua promoção. A inexistência do dado pode revelar a inexistência do interesse político, em tempos em que se acentuam os desgastes nas condições de vida de pós-graduandos. A perspectiva do engajamento estudantil permite lançar certas luzes pedagógicas sobre esse cenário.

Buckley (2017) indica o modelo de participação cidadã de Arnstein (1969) - exposto na Figura 1, a seguir como uma influência importante para os estudos em engajamento e participação estudantis. O pressuposto da autora é de que "participação cidadã é poder cidadão" (ARNSTEIN, 1969, p. 216) e que a redistribuição do poder permite a inclusão dos cidadãos que se encontram excluídos dos processos políticos em deliberações futuras. A participação cidadã traria assim os meios pelos quais aqueles que se encontram em situações subalternas dentro de sistemas 
políticos "podem induzir reforma social significativa que lhes permita partilhar dos benefícios da sociedade afluente" (ARNSTEIN, 1969, p. 216). A autora apresenta diferentes formas de participação que compõem oito degraus em uma "escada de participação".

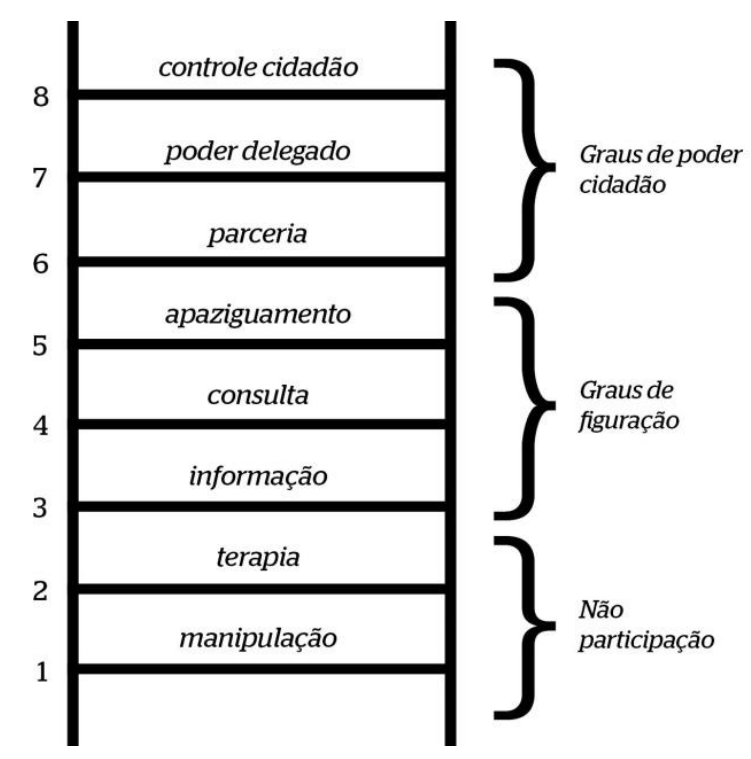

Figura 1. "Oito degraus em uma escada de participação cidadã".

Fonte: Adaptado de Arnstein (1969).

Tomando a escada de Arnstein (1969) como referência, é possível considerar que o poder instituído do Estado, exercido sobre a educação superior através da avaliação institucional, informa tipos específicos de participação estudantil. No nível de graduação, seria alcançado o quarto degrau da consulta, um grau de figuração em que as opiniões e os posicionamentos estudantis podem ser requeridos e ouvidos pelos gestores, mas não têm poder para garantir que suas demandas serão atendidas, "não havendo portanto garantia de mudança no status quo" (ARNSTEIN, 1969, p. 217). Já no nível da pós-graduação, os estudantes estão relegados ao degrau da manipulação, no patamar de não participação. Nesse estágio, o interesse de quem gere o sistema "não é habilitar as pessoas para participar 
no planejamento ou condução de programas, mas permitir que os detentores do poder 'eduquem' ou 'tratem' os participantes" (ARNSTEIN, 1969, p. 217).

Na tradicional estrutura acadêmica brasileira, só através da representação estudantil em comissões acadêmicas se pode galgar degraus de participação, atingindo graus de poder cidadão. Mas esse tipo de engajamento é restrito a poucos pelo formato representativo da governança universitária. Seguindo a perspectiva de Arnstein (1969), mesmo a representação discente estaria ainda nos graus de figuração, como uma estratégia de apaziguamento. E ainda, essas posições, mesmo estando disponíveis, nem sempre são ocupadas pelos estudantes. De fato, quando se observa a grande maioria dos estudantes que não está engajada nas lutas cotidianas do movimento estudantil, pode-se, como Leite (2010), não encontrar "nem ventos, nem resistências" em suas atitudes quanto à avaliação institucional, como atividade representativa de outros fazeres acadêmicos.

Observo que compreender hoje os estudantes e suas culturas significa adentrar o olhar para sua atividade ou comportamento individual mais do que para sua atuação coletiva e política. Os estudantes podem estar a atuar na realidade sem querer exatamente transformar a realidade. Destaco o redirecionamento das questões estudantis para outros polos de ação que exigem mais o envolvimento individual ou de pequenos grupos do que uma participação coletiva (LEITE, 2010, p. 23).

A hipótese da autora é que estar em ação processos de engendramento de subjetividades formatadas pela agenda produtivista neoliberal do individualismo possessivo. Outros dois fatores podem ser somados a essa reflexão. O primeiro é pedagógico: na educação superior, são insuficientes os esforços para tratar da participação política estudantil, seja em sua discussão, avaliação ou valorização. O segundo é político, encontrado nas palavras de Arnstein (1969, p. 216): "participação sem redistribuição do poder é um processo vazio e frustrante para aqueles sem poder. Ele permite que os detentores do poder aleguem que todas as partes foram consideradas, mas torna possível que apenas uma das partes se beneficie".

Talvez seja então interessante voltar a atenção para outros fenômenos associados, ou seja, formas de ativismos estudantis que não se encaixam nas normatividades das instituições. Apoiados em Trowler (2015), Macfarlane e Tomlinson (2017) classificam-nas de "engajamento como oposição", a desafiar as expectativas e delimitações convencionais do engajamento estudantil prescritivo. Elas podem, por exemplo, afetar atividades com greves, boicotes, protestos e outras demonstrações que busquem redefinir parâmetros didáticos-pedagógicos. Esse engajamento estudantil "marginal" poderia ter, nos termos de Aswhin e McVitty (2015), a forma de liderança na comunidade. E essa ruptura pode ter o lócus e o kairós da inovação pedagógica. 
Segundo uma suposição tradicional, ao se recusarem a seguir as regras do jogo que lhes são impostas, os estudantes estariam derivando em direção à anomia. Mas poderiam também estar rumando justamente em seu contrário, tensionando sua autonomia para buscar a repactuação da normatividade pedagógica discutindo fundamentos ético-políticos da própria prática acadêmica e questionando os limites mesmos da participação cidadã. Assim, o que pode parecer a recusa do engajamento pode ser também sua manifestação no sentido radical referido seja no léxico brasileiro registrado por Buarque de Hollanda Ferreira (1975), de ação com consciência e solidariedade, seja na teoria anglo-saxã originária recuperada por Wolf-Wendel, Ward e Kinzie (2009), de pactuação da experiência educacional.

Tal questionamento do estudante engajado pode se dar desde o modo mais formal do protesto irreverente de representantes estudantis nas reuniões colegiadas até a ocupação dos espaços das instituições de educação superior para discutir pautas de importância estratégica nacional, com valorização das dimensões de coletividade e horizontalidade (SFREDO MIORANDO, no prelo).

\section{Considerações finais: por onde construir formações emergentes}

Como apontam Aswhin e McVitty (2015, p.355), "há formas pelas quais o engajamento estudantil é apresentado aos estudantes, formas pelas quais essa proposta é posta em prática nos processos institucionais, e formas pelas quais os estudantes se engajam nesses processos". O engajamento estudantil na educação superior brasileira merece ser estudado a partir de suas limitações. De modo geral, os estudantes são "ouvidos, porém não escutados". Quando se consideram os formatos de participação apresentados por Arnstein (1969), os próprios procedimentos de avaliação reforçam subjetividades estudantis capitalistas, circunscrevendo as possibilidades de engajamento estudantil dentro do modelo neoliberal criticado por Zepke (2018). Quando se considera que o sistema é estruturado em políticas que desativam energias emancipatórias e as direcionam para a competitividade individualista, percebe-se o risco de que o engajamento estudantil seja ideologicamente capturado como apenas mais uma "vantagem competitiva".

Isso leva então a problematizar que a introdução da discussão sobre o student engagement deve se orientar pela indagação de como a estrutura acadêmica brasileira, através de suas instituições, de seus cursos e de seus profissionais, estimula o engajamento estudantil de modo a cultivar as energias participativas de seus estudantes. A partir desta revisão, parece que, para desenvolver o engajamento estudantil no Brasil, é preciso, como em Córdoba, desenvolver um pensamento alternativo de alternativas que promova o estudante como sujeito político. Trata-se, voltando a Arnstein (1969), de formar para escalar a escada da participação social, através da qual "aqueles que não são 'ninguém' em várias arenas tentam se tornar 'alguéns' com poder suficiente para tornar as instituições-alvo responsivas a suas perspectivas, aspirações e necessidades" (p. 217). Caberia então desenvolver a participação na 
acepção que Leite e colaboradores (2009, p. 219), estudando a avaliação institucional, identificam como "criativa", isto é, aquela que "inclui participação nas experiências, nos sentimentos e conhecimentos; ocorre em processos anteriores à disputa pelas decisões; busca o contato com o outro para ver e entendê-lo como outro; restabelece a união com as contradições de si mesmo".

Ironicamente, o próprio caráter do estudante como "transindivíduo", frequentemente utilizado para desqualificar sua legitimidade política e cercear sua participação, é o que o identifica, na visão de Darcy Ribeiro, como agente da transformação democrática:

Somente os decididos a encarnar os interesses da maioria da população e a defender, a qualquer custo, o desenvolvimento nacional autônomo poderão modelar uma Universidade capaz de atuar como agência de aceleração evolutiva da sociedade. E dentro da Universidade, só o corpo estudantil oferece suficiente garantia de não atuar a serviço dos objetivos de autoperpetuação das hierarquias internas e de defesa dos interesses das velhas clientelas.

Nestas circunstâncias, o problema fundamental da reforma não está na técnica da nova estrutura, mas na determinação do conteúdo de poder que marcará o rumo e o ritmo do processo de transformação. Este iniludível imperativo indica o cogoverno das universidades, institutos centrais, faculdades e departamentos, pelos professores e alunos, como o requisito básico da edificação da Universidade necessária (RIBEIRO, 1975, p. 248).

$\mathrm{Na}$ tradição latino-americana do estudante engajado, o engajamento estudantil rompe os limites das atividades de ensino em sala de aula. Politizado, ele ocupa universidades, toma as ruas e interroga a política nacional. Ele não pode ser entendido sem recurso tanto a categorias de ação política quanto à análise social dos afetos. A tradição do movimento estudantil latino-americano e os fatos sociais e históricos brasileiros recentes podem guardar a lição de que a pesquisa sobre o engajamento estudantil no Brasil - e alhures - deve considerar o processo instituinte da presença política do estudante. E que tal presença - uma presença crítica, atuante, engajada - é fundamental não apenas para o desempenho cotidiano das funções acadêmicas, mas para a garantia do próprio futuro da educação superior como instituição. Afinal, nas palavras de Milton Santos,

A universidade, aliás, é, talvez, a única instituição que pode sobreviver apenas se aceitar críticas, de dentro dela própria, de uma ou outra forma. Se a universidade pede aos seus participantes que calem, ela está se condenando ao silêncio, isto é à morte, pois seu destino é falar. [...] E é a partir da ideia sempre renovada de universidade que julgamos as universidades concretas e sugerimos mudanças. De outro modo, compactuamos com equívocos e erros e acabamos, nós próprios, praticando equívocos e erros (SANTOS, 1997, p. 17). 


\section{Referências}

(As traduções das citações literais de originais em língua estrangeira são livres.)

ARNSTEIN, Sherry R. A ladder of citizen participation. Journal of the American Institute of Planners, v. 35, n. 4, p. 216-224, jul. 1969.

ASTIN, Alexander. What Matters in College? Four Critical Years Revisited. San Francisco: Jossey-Bass Publishers, 1993.

ASWHIN, Paul; MCVITTY, Debbie. The meanings of student engagement: implications for policies and practices. In: CURAJ, Adrian et al. (Eds.). The European Higher Education Area: Between critical reflections and future policies. Dordrecht: Springer, 2015. p. 343-359.

BUARQue DE HOLlandA FERREIRA, Aurélio. Novo Dicionário da Língua Portuguesa. Rio de Janeiro: Nova Fronteira, 1975. BUCKLEY, Alex. The ideology of student engagement research. Teaching in Higher Education, v. 23, n. 6, p. 718-732, 2018.

CHEN, p. Daniel; MATHIES, Charles. Assessment, evaluation, and research. New Directions for Higher Education, n. 175, p. 85-92, fall 2016.

CLARK, Burton R. Development of the sociology of higher education. Sociology of Education, v. 46, n. 1, p. 2-14, winter 1973.

ENTWISTLE, Noel. Identifying distinctive approaches to studying. Higher Education, v. 8, n. 4, p. 365-380, jul. 1979.

ENTWISTLE, Noel; RAMSDEN, Paul. Understanding Student Learning. London: Croom Helm, 1983.

ENTWISTLE, Noel; MCCUNE, Velda; SCHEJA, Max. Student learning in context: understanding the phenomenon and the person. In: VERSCHAFFEL, Lieven; DOCHY, Filip; BOEKAERTS, Monique; VOSNIADOU, Stella (Eds.). Instructional psychology: past, present and future trends. Oxford: Elsevier, 2006. p. 131-148.

FELDMAN, Kenneth A.; NEWCOMB, Theodore. The impact of college on students. San Francisco: Jossey-Bass, 1976.

FORACHI, Marialice. O estudante e a transformação da sociedade. São Paulo: Editora Nacional, 1965.

GOLDMANN, Lucien. Epistemologia e filosofia política. Porto: Presença, 1984.

GUILHON ALBUQUERQUE, José A. Movimento estudantil e consciência social na América Latina: teoria e método sociológico. Rio de Janeiro: Paz e Terra, 1977.

HABERMAS, Jürgen et al. Student und politik: eine soziologische Untersuchung zum politischen Bewußtsein Frankfurter Studenten. Neuwied: H. Luchterhand, 1961.

HEALEY, Mick; MASON O’CONNOR, Kristine; BROADFOOT, Patricia. Reflections on engaging students in the process and product of strategy development for learning, teaching, and assessment: an institutional case study. International Journal for Academic Development, v. 15, n. 1, p. 19-32, 2010.

INEP - INSTITUTO DE ESTUDOS E PESQUISAS EDUCACIONAIS ANÍSIO TEIXEIRA. Sinopses Estatísticas do Enade: Enade 2016. 2017. Disponível em: <http://portal.inep.gov.br/web/guest/sinopses-estatisticas-do-enade>. Acesso em: 9 maio 2018. 
INGENIEROS, José. Propagación universitaria. La Revolución universitaria se extiende ya por toda la américa. Integración y Conocimiento, Córdoba, v. 2, n. 7, p. 121, 2017 [1924].

KAHU, Ella R. Framing student engagement in higher education. Studies in Higher Education, v. 38, n. 5, p. 758-773, 2013.

KROTSCH, Pedro. Los estudiantes universitarios como actores de reformas em América Latina: la cultura de los jóvenes y la crisis de la institución. Avaliação, Campinas; Sorocaba, v. 9, n. 4, p. 99-119, 2004.

LEITE, Denise. Aprendizagem e consciência social na universidade. Tese (Doutorado) - Universidade Federal do Rio Grande do Sul. Faculdade de Educação. Programa de Pós-Graduação em Educação, Porto Alegre, BR-RS, 1990.

LEITE, Denise. A aprendizagem política do estudante universitário. Educação e Realidade, Porto Alegre, v. 17, p. $25-31$, 1992.

LEITE, Denise. Reformas universitárias: Aavaliação institucional participativa. Petrópolis: Vozes, 2005.

LEITE, Denise. Estudantes e avaliação. Avaliação, Campinas; Sorocaba, v. 15, n. 3, p. 9-27, nov. 2010.

LEITE, Denise. A pedagogia da Reforma de Córdoba. Integración y conocimiento, Córdoba, v.1, n. 8, p. 37-53, 2018.

LEITE, Denise; BRAGA, Ana; GENRO, Maria Elly; CAMPANI, Adriana; STEFFEN, Alexandre. Inovação na zona cinzenta de transição. Cadernos de Educação, Pelotas, n. 8, p. 75-95, jan./jun. 1997.

LEITE, Denise; GENRO, Maria Elly Herz; BRAGA, Ana Maria e Souza. Inovações pedagógicas e demandas ao docente na universidade. In: LEITE, Denise; GENRO, Maria Elly Herz; BRAGA, Ana Maria e Souza (Orgs.). Inovação e pedagogia universitária. Porto Alegre: UFRGS Editora, 2011. p. 19-39.

LEITE, Denise; GENRO, Maria Elly; CAMPOS, Márcia; NUNES, Ana Karin; WIELEWICKI, Hamilton de Godoy; RUBIN, Marlize; DALPIAZ, Maria Martha; MACHADO, Geraldo Ribas; BASSI, Luis Augusto Peukert. Avaliação participativa: constatações a aprendizagens. In: LEITE, Denise. (Org.). Avaliação participativa e qualidade: os atores locais em foco. Porto Alegre: Sulina; Editora IPA, 2009. p. 209-224.

MACFARLANE, Bruce. The higher education research archipelago. Higher Education Research \& Development, v. 31, n. 1, p. 129131, feb. 2012.

MACFARLANE, Bruce; TOMLINSON, Michael. Critiques of student engagement. Higher Education Policy, v. 30, n. 1, p. 5-21, mar. 2017.

MARIÁTEGUI, José Carlos. La reforma universitaria. Integración y conocimiento, Córdoba, v.1, n. 6, p. 91-106, 2017 [1928].

MARTINS FILHO, João Roberto. Movimento estudantil e ditadura militar: 1964-1969. Campinas: Papirus, 1987.

MARTON, F.; SALJO, R. On qualitative differences in learning: I - outcomes and process. British Journal of Educational Psychology, v. 46, n. 1, p. 4-11, feb. 1976.

NSSE - NATIONAL SURVEY OF STUDENT ENGAGEMENT. About NSSE. 2018. Disponível em: <http://nsse.indiana.edu/html/ about.cfm>. Acesso em: 29 jul. 2018.

PASCARELLA, Ernest T.; TERENZINI, Patrick T. How college affects students. San Francisco: Jossey-Bass Publishers, 1991. PERRY, William G. Forms of intellectual and ethical development in college years. New York: Rinehart and Winston, 1970. 
POERNER, Arthur José. O poder jovem: história da participação política dos estudantes brasileiros. 2. ed. Rio de Janeiro: Civilização Brasileira, 1979.

PORTANTIERO, Juan Carlos. Estudiantes y política en América Latina. México: Siglo XXI, 1978.

RIBEIRO, Darcy. A universidade necessária. 2. Ed. Rio de Janeiro: Paz e Terra, 1975.

RICHARDSON, John T.; EYSENCK, Michael W.; PIPER, David Warren (Eds.). Student learning: research in education and cognitive psychology. England: SRHE \& Open University, 1987.

RIOS, José Arthur. The university student and Brazilian society. East Lansing: Latin American Studies Center / Michigan State University, 1971.

SANFELICE, José Luís. Movimento estudantil: a UNE na resistência ao golpe de 64. São Paulo: Cortez Editora, 1986.

SANTOS, Milton. O intelectual e a universidade estagnada. Revista Adusp, São Paulo, n. 11, p. 16-20, out. 1997.

SFREDO MIORANDO, Bernardo. Student engagement in Brazilian higher education and its socio-political dimension. In: TANAKA, Masahiro (Ed.) Student engagement in quality assurance. Abingdon: Routledge, no prelo.

TROWLER, Vicki. Negotiating contestations and 'chaotic conceptions': Engaging 'non-traditional' students in higher education. Higher Education Quarterly, v. 69, n. 3, p. 295-310, jul. 2015.

TUNNERMANN BERNHEIM, Carlos. Noventa años de la Reforma Universitária de Córdoba (1918-2008). Buenos Aires: CLACSO, 2008.

UNE - UNIÃO NACIONAL DOS ESTUDANTES. A UNE contra o SNI. São Paulo: Editora Alfa-Ômega, 1987.

WOLF-WENDEL, Lisa; WARD, Kelly; KINZIE, Jillian. A tangled web of terms: The overlap and unique contribution of involvement, engagement, and integration to understanding college student success. Journal of College Student Development, v. 50, n. 4, p. 407-428, jul./aug. 2009.

ZEPKE, Nick. Understanding teaching, motivation and external influences in student engagement: How can complexity thinking help? Research in Post-compulsory Education, v. 16, n. 1, p. 1-24, 2011.

ZEPKE, Nick. Student engagement research in higher education: questioning an academic orthodoxy. Teaching in Higher Education, v. 19 , n. 6, p. 697-708, 2014

ZEPKE, Nick. Student engagement in neo-liberal times: what is missing? Higher Education Research \& Development, v. 37, n. 2, p. 433-446, 2018.

Recebido em: julho/2018

Aceito em: outubro /2018

Endereço para correspondência:

Bernardo Sfredo Miorando <bernardo.sfredo@gmail.com>

Av. Paulo Gama, s/no, prédio 12.201 - 7oandar

90046-900, Porto Alegre, RS, Brasil 